\title{
Near-threshold fatigue crack growth behaviour of a ferritic stainless steel at elevated temperatures
}

\author{
Kamel Makhlouf and J.W. Jones
}

Near-threshold fatigue crack propagation (FCP) behaviour has been studied in an $18 \% \mathrm{Cr}-\mathrm{Nb}$ stabilized ferritic stainless steel at temperatures ranging from room temperature to $700^{\circ} \mathrm{C}$. At a stress ratio of 0.1 increasing the test temperature from room temperature to $500^{\circ} \mathrm{C}$ resulted in an increase of the growth rates in the midrange growth regime and a sharply defined threshold at a $\Delta K$ level higher than the room temperature threshold, giving rise to a crossover type of behaviour. At temperatures higher than $500^{\circ} \mathrm{C}$ increased crack tip plasticity predominates and the fatigue crack growth rates decrease smoothly with a decreasing value of $\Delta K$ to thresholds lower than the room temperature value. Crack closure measurements suggest that asperity-induced closure dominates at room temperature but transitions to plasticity-induced closure dominate at $500^{\circ} \mathrm{C}$. A constant- $K_{\max }$ increasing $R$-ratio (CKIR) test procedure was utilized at room temperature and at $500^{\circ} \mathrm{C}$ in an attempt to identify near-threshold FCP data in the absence of crack closure. However, the type of crossover behaviour identified with constant $R$-ratio tests at room temperature and $500^{\circ} \mathrm{C}$ was also observed in the CKIR tests. This is attributed to a change in the closure mechanism from a roughness-induced one to one involving crack tip plasticity.

Key words: crack propagation; crack closure; crossovers

In recent years, considerable effort has been devoted to the study of fatigue thresholds and near-threshold fatigue crack propagation in metals where growth rates of the order of $10^{-9} \mathrm{~m} /$ cycle and lower are observed. ${ }^{1}$ It is well known that near-threshold fatigue crack propagation rates and the values of the stress intensity range at threshold, $\Delta K_{\text {th }}$, are extremely sensitive to the mechanical and microstructural variables. Mean stress, characterized by the load ratio, $R$, prior stress history, crack size, cyclic frequency, monotonic and cyclic yield strengths, grain size, grain boundary composition and environment are important variables.

Procedures such as ASTM E647-88A (Ref. 2) are available to characterize the type of threshold behaviour, although it is recognized that data generated with low $R$-ratio $\Delta K$ decreasing test methods may be non-conservative. The nonconservative nature of such data can be attributed primarily to the development of significant crack closure in the nearthreshold regime, ${ }^{3}$ especially at low $R$-values.

A number of crack closure mechanisms have been identified and used in various models to explain near-threshold behaviour. At elevated temperature the accumulation of oxide within the crack has been shown to enhance crack closure (oxide-induced closure). With increasing temperature an oxide layer is produced on the fracture surfaces over time and thickened by fretting during which the oxide repeatedly ruptures, reforms and compacts between the crack faces. This thicker oxide can wedge the crack open and cause the $\Delta K_{\mathrm{th}}$ values to increase. ${ }^{4,5}$ Roughness-induced crack closure (frequently called asperity-induced crack closure) has been attributed to the rough nature of the fracture surfaces, and is enhanced by the mismatch of these asperities when a modeII component of crack opening is present. ${ }^{6,7}$ In some instances, plasticity-induced closure, as originally suggested by Elber, ${ }^{8}$ has also been observed. This arises from elastic constraints acting on the plastically stretched material in the wake of the crack tip.

The consequence of these closure mechanisms is to lower the crack growth rates by reducing the nominal applied stress intensity factor $\Delta K$ experienced at the crack tip to some lower value defined as the effective stress intensity factor, $\Delta K_{\text {eff }}=$ $K_{\max }-K_{\mathrm{cl}}$. The complicated nature of the effect of closure on fatigue crack propagation and fatigue threshold has led to attempts to develop new test procedures that identify crack propagation behaviour in the absence of crack closure.

A modified test procedure involving a methodology with constant maximum stress intensity and decreasing $\Delta K$ has been used to identify near-threshold crack propagation behaviour in the absence of detectable amounts of crack closure. This technique, suggested by Docker et al, ${ }^{9}$ has recently been used by Hertzberg et $a l^{10}$ and Herman ${ }^{11}$ to predict short-crack growth behaviour in a 2090-T8E4 aluminium-lithium alloy at room temperature. The constant$K_{\text {max }}$, increasing $R$-ratio (CKIR) testing procedure consists of keeping $K_{\max }$ constant during the test and approaching the threshold by increasing $K_{\min }$. By maintaining $K_{\max }$ constant the mean stress and associated $R$-values continually increase 


\begin{tabular}{lccccccccc}
\hline Composition (wt. \%) & $\mathrm{Fe}$ & $\mathrm{Cr}$ & $\mathrm{C}$ & $\mathrm{Mn}$ & $\mathrm{Si}$ & $\mathrm{Ti}$ & $\mathrm{P}$ & $\mathrm{S}$ & $\mathrm{Nb}$ \\
\hline $18 \% \mathrm{Cr}-\mathrm{Nb}$ & bal & 18.04 & 0.031 & 0.33 & 0.473 & 0.206 & 0.031 & 0.015 & 0.706 \\
\hline
\end{tabular}

as $\Delta K$ decreases, resulting in the generation of near-threshold fatigue crack propagation data under conditions where crack closure should be negligible. Therefore, the fatigue crack propagation data generated by the CKIR procedure in the near-threshold regime should represent the intrinsic-crack propagation behaviour of the material, and the measured value of $\Delta K_{\mathrm{th}}$ should therefore correspond to the effective stress intensity at threshold.

The present research investigates the utility of the CKIR methodology for determining near-threshold crack propagation at elevated temperatures, where crack closure behaviour and the nature of crack propagation are complicated by environmental and time-dependent effects. A series of crack growth studies, over a range of temperatures, has been performed on a ferritic stainless steel using both the conventional constant- $R, \Delta K$ decreasing (ASTM E647-88A) test procedure and the more recent CKIR methodology.

\section{Material}

The test material examined in this investigation is an $18 \% \mathrm{Cr}-\mathrm{Nb}$ stabilized ferritic stainless steel supplied as coldrolled sheet. This material is of particular interest because of its resistance to corrosion and oxidation at elevated temperatures. The carbon content is kept as low as is economically feasible in order to improve the toughness (ductility) and to minimize sensitization, which occurs through precipitation of chromium carbides. As a consequence of the low carbon content the room temperature yield strength is only $324 \mathrm{MPa}$. The chemical composition and the mechanical properties at different temperatures of this material are listed in Tables 1 and 2, respectively. ${ }^{12}$

\section{Fatigue crack growth testing}

All the fatigue crack growth tests were performed on electropolished single-edge notch (SEN) specimens with a width of $25.4 \mathrm{~mm}$ and a nominal thickness of $1.42 \mathrm{~mm}$. The tests were conducted at room and elevated temperatures at different $R$-ratios in laboratory air using a $100 \mathrm{kN}$ load cell MTS servohydraulic test system. A DC electric potential drop technique was used for crack growth monitoring in conjunction with optical measurements for room temperature experiments.

Table 2. Mechanical properties (see Ref. 12)

\begin{tabular}{lccc}
\hline $\begin{array}{l}\text { Temperature } \\
\left({ }^{\circ} \mathrm{C}\right)\end{array}$ & $\sigma_{y}(\mathrm{MPa})$ & UTS (MPa) & $\begin{array}{c}\text { Elongation } \\
(\%)\end{array}$ \\
\hline 25 & 324 & 471 & 35.5 \\
400 & 220 & 376 & 25.1 \\
500 & 196 & 345 & 22.9 \\
600 & 170 & 310 & - \\
700 & 88 & 112 & 28.1 \\
\hline
\end{tabular}

At elevated temperatures optical measurements of the crack lengths were difficult because of slight oxidation of the specimen surface, and only the DC potential drop technique was used. A constant current of $10 \mathrm{~A}$ was passed through the specimen at all temperatures. All the fatigue tests were performed at a frequency of $15 \mathrm{~Hz}$ using a sinusoidal waveform. For tests performed at elevated temperature the system was equipped with a resistance furnace. Two thermocouples were attached to the specimen near the crack path to monitor the temperature, which was controlled to within $\pm 1{ }^{\circ} \mathrm{C}$.

Two test procedures were used to determine the $\Delta K$ threshold. In the first a constant- $R, \Delta K$ decreasing test, as described by ASTM E647-88A (Ref. 2) was employed. In this procedure $\Delta K, K_{\max }$ and $K_{\min }$ decrease exponentially with increasing crack length according to the unloading schedule, which is given by

$$
\Delta K=\Delta K_{0} \exp \left[c\left(a-a_{0}\right)\right]
$$

where $\Delta K$ and $\Delta K_{0}$ are the instantaneous and initial stress intensity factors, respectively, $a$ and $a_{0}$ are the current and initial crack lengths, respectively, and $c$ is the stress intensity factor gradient defined by

$$
c=(1 / \Delta K)(\mathrm{d} \Delta K / \mathrm{d} a)
$$

$c$ was held constant at $-0.07874 \mathrm{~mm}^{-1}$, although experiments using a value of $-0.04 \mathrm{~mm}^{-1}$ gave similar results. A schematic illustration of this test is shown in Fig. 1(a). For the specimen geometry used the stress intensity range was calculated by

$$
\Delta K=\Delta \sigma \vee a Y(a / W)
$$

where

$$
\begin{aligned}
Y(a / W)= & 1.99-0.41(a / W) \\
& +18.7(a / W)^{2}-38.48(a / W)^{3} \\
& +53.83(a / W)^{4}
\end{aligned}
$$

$\Delta \sigma$ is the applied stress range and $W$ is the specimen width. ${ }^{13}$ Threshold was identified as the stress intensity range for which growth rates of the order of $10^{-10} \mathrm{~m} /$ cycle were reached.

In the second test procedure CKIR, $K_{\max }$ was kept constant and $K_{\min }$ was increased in small increments with the magnitude of the increments decreasing continuously as $\Delta K_{\text {th }}$ was approached, resulting in an increase in the $R$-ratio as crack length increased. A schematic illustration of the CKIR testing procedure is shown in Fig. 1(b). Two mid-range $K_{\max }$ levels of 17 and $24 \mathrm{MPa} V \mathrm{~m}$ were used at $500^{\circ} \mathrm{C}$ and a value of $K_{\max }$ of 17.7 was used at $20^{\circ} \mathrm{C}$. The initial $R$-ratio for all CKIR tests was 0.1 . In the early stage of these tests the $R$ increment was 0.1. By the end of the tests incremental increases in $R$-ratio, and therefore in $\Delta K$, of only 0.02 were produced. In order to assure the absence of load history effects the crack growth rates were allowed to stabilize before changes in load were made. For all the tests the crack growth rates, $\mathrm{d} a / \mathrm{d} N$, were calculated from the $a-N$ data using a seven-point incremental polynomial method or the secant method, both described by ASTM E647-88A. ${ }^{2}$ 


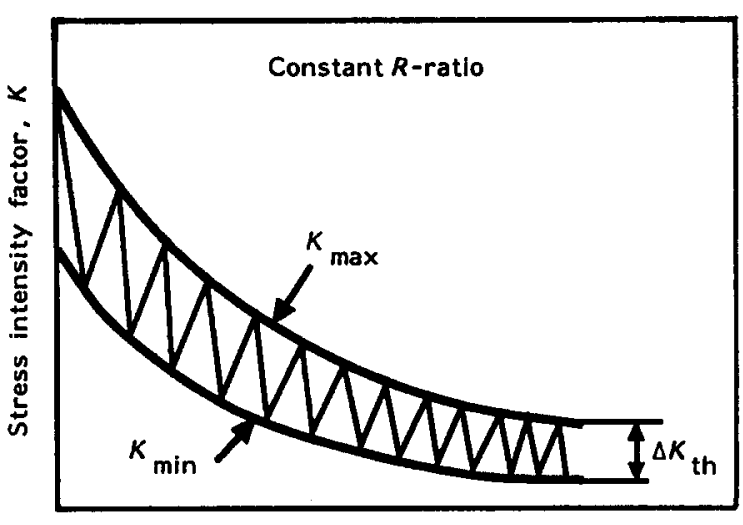

a

Crack length

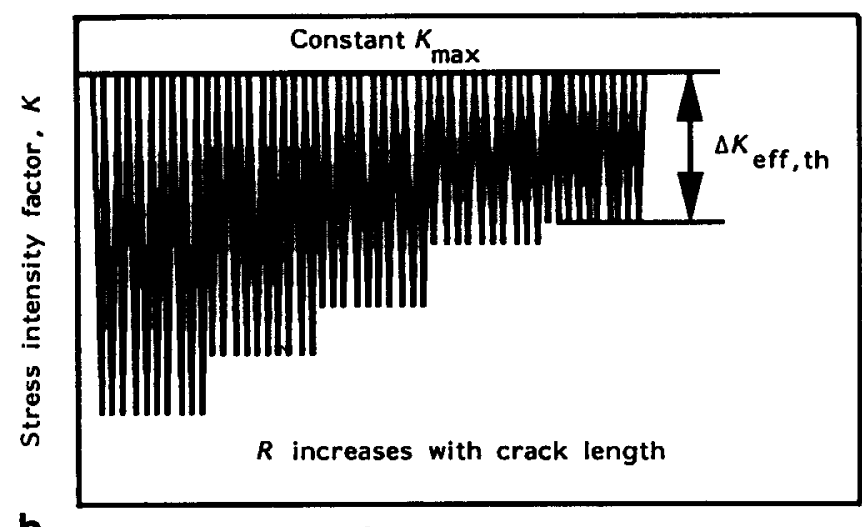

Crack length

Fig. 1 Schematic representation of two $\Delta K$-decreasing test procedures for threshold determination: (a), constant- $R$ procedure; (b), constant $-K_{\max }$ increasing $-R$ procedure

Crack closure measurements were performed using a crack mouth displacement (CMD) gauge attached to the front face of the specimen through the furnace wall. The CMD gauge was equipped with $127 \mathrm{~mm}$ long quartz rods. The output of the CMD gauge and load on the specimen were recorded on an $X Y$ recorder. The crack closure load was obtained from the unloading portion of the load against crack mouth opening displacement (CMOD) curves, which were recorded at a frequency of $0.1 \mathrm{~Hz}$. The crack closure level was defined at the point where the load against displacement curve began to deviate from the unloading linear elastic line. This technique has been described in greater detail elsewhere. ${ }^{14,15}$ Closure measurements were made at a stress ratio of 0.3 for the test at room temperature and $0.1,0.3$ and 0.5 for tests at $500^{\circ} \mathrm{C}$.

\section{Results}

\section{Effects of temperature on $\Delta \boldsymbol{K}_{\text {th }}$}

Near-threshold fatigue crack propagation behaviour using a constant- $R$-ratio of $0.1, \Delta K$ decreasing procedure at room temperature, 500,600 and $700{ }^{\circ} \mathrm{C}$ for the $18 \% \mathrm{Cr}-\mathrm{Nb}$ stabilized ferritic stainless steel is shown in Fig. 2. In general the midrange growth rates increased and the threshold stress intensity significantly decreased with increasing test temperature. However, at $500^{\circ} \mathrm{C}$, a somewhat more complicated behaviour near $\Delta K_{\text {th }}$ was observed. The mid-range growth rates at $500^{\circ} \mathrm{C}$ increased by a factor of approximately three over the room temperature values and at a value of $\Delta K$ of approximately $12 \mathrm{MPa} V_{\mathrm{m}}$ a sharply defined threshold was observed. As a consequence $\Delta K_{\text {th }}$ increased from $8.2 \mathrm{MPa} V_{\mathrm{m}}$ at room temperature to $11.8 \mathrm{MPa} V \mathrm{~m}$ at $500^{\circ} \mathrm{C}$. This type of behaviour resulted in the crossing of the fatigue crack growth curves or the 'crossover' phenomenon. No crossover relative to the room temperature behaviour was observed at 600 or $700{ }^{\circ} \mathrm{C}$, and the fatigue crack growth rates decreased smoothly with decreasing $\Delta K$ down to the lowest threshold levels tested. The test at $700{ }^{\circ} \mathrm{C}$ gave the highest growth rates in the midrange regime (more than one order of magnitude higher than the room temperature rates) and the lowest value of $\Delta K_{\mathrm{th}}$ of $5.1 \mathrm{MPa} V_{\mathrm{m}}$. At $700^{\circ} \mathrm{C}$, the crack tip plasticity limited the fatigue crack growth tests to $K_{\max }$ values lower than $10 \mathrm{MPa}$ $V \mathrm{~m}$. At $600^{\circ} \mathrm{C}$, a value of $\Delta K_{\text {th }}$ of $6.55 \mathrm{MPa} V_{\mathrm{m}}$ was observed.

\section{$R$-ratio effects and $K_{\max }$ testing (at $500{ }^{\circ} \mathrm{C}$ )}

The load ratio dependence of near-threshold fatigue crack propagation was investigated at $500^{\circ} \mathrm{C}$ at three load ratios of
0.1, 0.3 and 0.5, and the results are shown in Fig. 3. Similar to the behaviour reported for the other low-strength materials, ${ }^{16}$ mid-range growth rates ( $\mathrm{da} / \mathrm{d} N>5 \times 10^{-9} \mathrm{~m} /$ cycle) are relatively insensitive to load ratio and all the fatigue crack growth curves tend to converge at higher $\Delta K$ levels. However, at near-threshold levels ( $\mathrm{d} a / \mathrm{d} N<5 \times 10^{-9} \mathrm{~m} /$ cycle), the growth rates are markedly increased, and the threshold values are substantially decreased with increasing $R$-ratio. At $500^{\circ} \mathrm{C}$, $\Delta K_{\text {th }}$ decreased from 11.8 to $6.3 \mathrm{MPa} V_{\mathrm{m}}$ when the stress ratio increased from 0.1 to 0.5 . The value of $\Delta K_{\text {th }}$ at $R=$ 0.3 was $9.8 \mathrm{MPa} \vee \mathrm{m}$. The threshold condition at these $R$ ratios corresponds to a common maximum stress intensity, $K_{\text {th, max }}$ of approximately $13.2 \mathrm{MPa} V \mathrm{~m}$.

Also shown in Fig. 3 are the fatigue crack propagation data generated by the CKIR test procedure at $500^{\circ} \mathrm{C}$. It is clear that the near-threshold fatigue crack propagation rates generated by the CKIR test are relatively equivalent to the

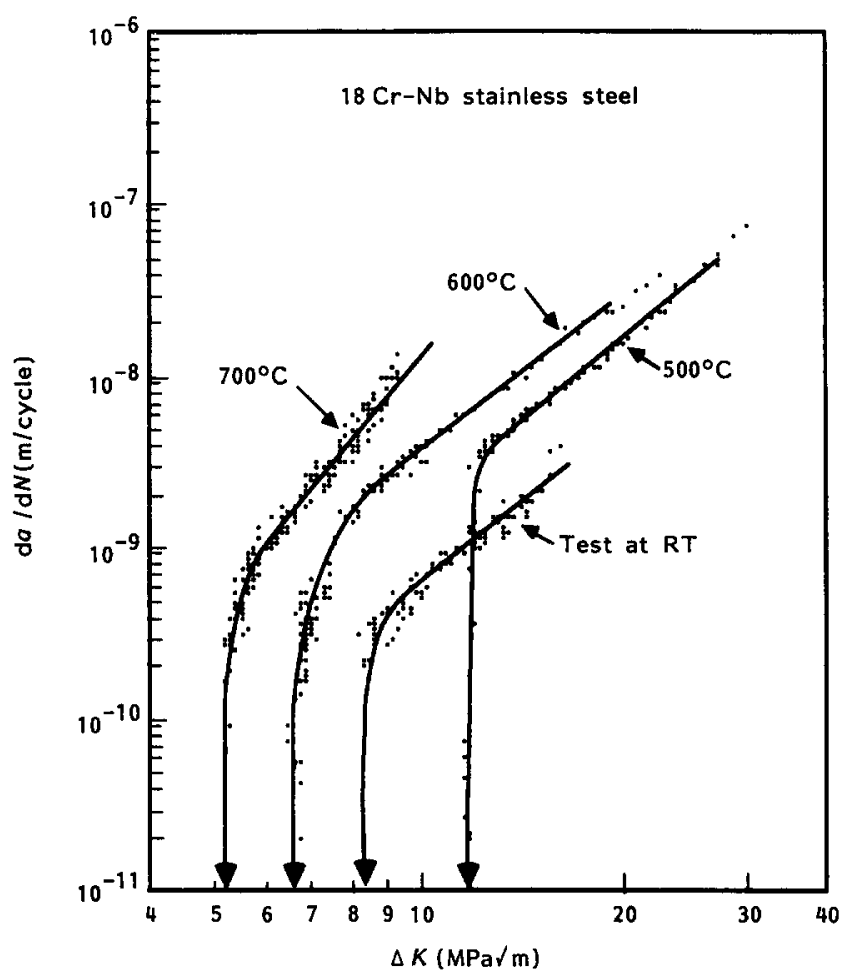

Fig. 2 Influence of temperature on the threshold stress intensity and near-threshold fatigue crack growth behaviour of $18 \%$ $\mathrm{Cr}-\mathrm{Nb}$ ferritic stainless steel. Tests conducted at $R=0.1, f=$ $15 \mathrm{~Hz}$ 


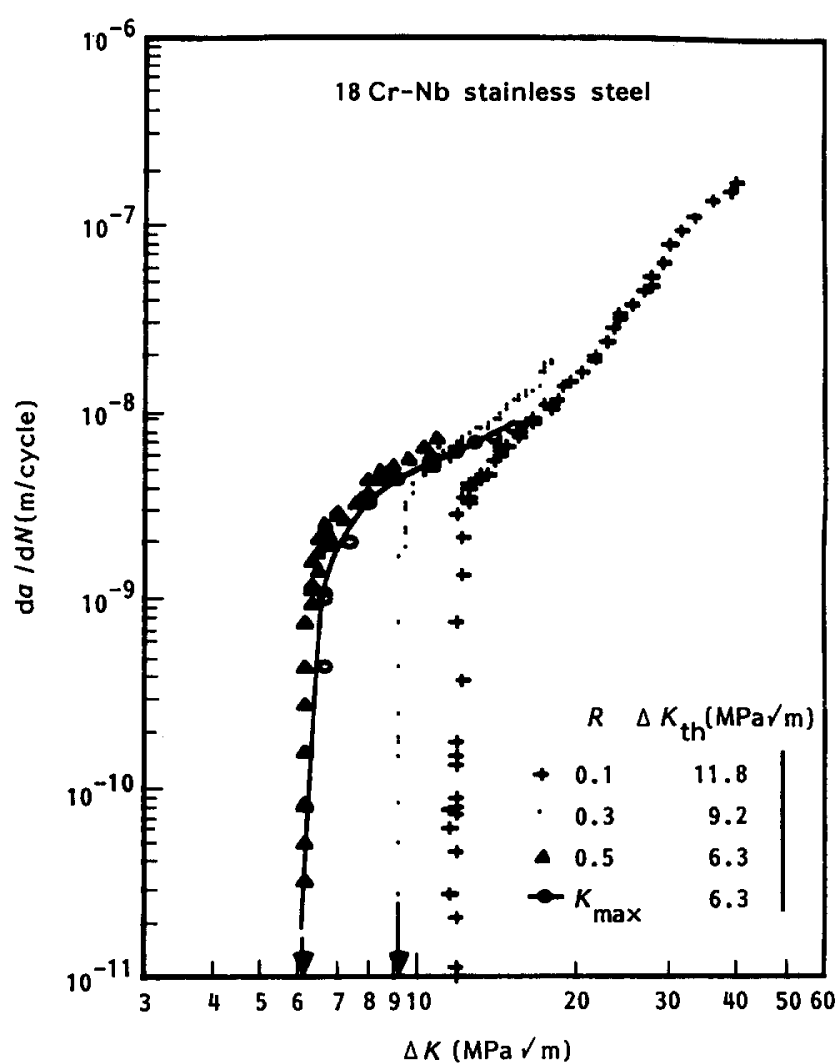

Fig. 3 Variation of fatigue crack growth rates with alternating stress intensity factor for $18 \% \mathrm{Cr}-\mathrm{Nb}$ ferritic stainless steel at different load ratios, $T=500^{\circ} \mathrm{C}, f=15 \mathrm{~Hz}$. The full curve is for the CKIR test results

rates generated by the conventional constant $R, \Delta K$-decreasing testing at high $R$-ratios. Using the CKIR technique values of $\Delta K_{\mathrm{th}}=6.3 \mathrm{MPa} V \mathrm{~m}$ and $R=0.61$ (for an initial value of $K_{\max }$ of $17 \mathrm{MPa} \vee \mathrm{m}$ ) were obtained at $500^{\circ} \mathrm{C}$. Although not shown in Fig. 3 an additional CKIR test at $500^{\circ} \mathrm{C}$ with an initial value of $K_{\max }$ of $24 \mathrm{MPa} V \mathrm{~m}$ produced a value of $R$ of 0.74 at threshold and yielded the same $\Delta K_{\text {th }}$ of $6.3 \mathrm{MPa}$ $V_{\mathrm{m}}$. These test results suggest that the CKIR test procedure provides a unique threshold and that $\Delta K_{\text {th }}$ at $500^{\circ} \mathrm{C}$ is independent of $R$-ratio for values above 0.5 .

\section{Crossover phenomenon}

The crossover phenomenon, which occurred between room temperature and $500^{\circ} \mathrm{C}$, has been studied in more detail using constant- $R, \Delta K$-decreasing tests at different $R$-ratios and the CKIR testing procedure. Figs $4(\mathrm{a})$ and (b) show fatigue crack growth data at room temperature and $500^{\circ} \mathrm{C}$ for $R=0.1$ and 0.5 respectively, whereas Fig. 4(c) shows the results of the CKIR testing at both temperatures where near-threshold growth rates were generated at stress ratios of 0.74 at room temperature and 0.61 at $500^{\circ} \mathrm{C}$. It is evident that at all $R$ ratios, including very high ones generated by the CKIR test procedure, as the test temperature was raised from room temperature to $500^{\circ} \mathrm{C} \Delta K_{\text {th }}$ increased over the room temperature values, and the region-II crack growth rates became higher, resulting in the crossover type of behaviour.

The dependence of $\Delta K_{\text {th }}$ on $R$-ratio at $500^{\circ} \mathrm{C}$ and room temperature is summarized in Fig. 5 for all the tests performed. The results indicate that at all $R$-ratios investigated, for a constant value of $R, \Delta K_{\text {th }}$ at $500^{\circ} \mathrm{C}$ was always higher than the room temperature value. Moreover, at both temperatures, $\Delta K_{\text {th }}$ was sensitive to variation of $R$-ratio only at $R$-ratios lower than a critical value, $R_{\mathrm{c}}$, that was characteristic for each temperature. At $500^{\circ} \mathrm{C}, \Delta K_{\text {th }}$ depended on $R$ for $R$-ratios lower than 0.5 and remained constant above that value. At room temperature the critical $R$-ratio was approximately 0.57 . Above these critical $R$-ratios $\Delta K_{\text {th }}$ remained constant and was equal to the values of $\Delta K_{\text {th }}$ generated using the CKIR test procedure. The dependence of $\Delta K_{\mathrm{th}}$ on $R$-value is generally explained in terms of crack closure.

\section{Crack closure}

Crack closure levels were monitored throughout the course of the constant- $R, \Delta K$-decreasing test procedure using the compliance technique. Fig. 6 shows the relationships between $K_{\mathrm{cl}} / K_{\max }$ and $K_{\max }$ obtained for $R=0.3$ at room temperature and for $R=0.1,0.3$ and 0.5 at $500{ }^{\circ} \mathrm{C}$ where $K_{\mathrm{cl}}$ is the crack closure stress intensity factor. As $K_{\max }$ decreases from 17.7 $\mathrm{MPa} \vee \mathrm{m}$ to the threshold level, the closure data for $R$ $=0.3$ at room temperature show an increase in the magnitude of $K_{\mathrm{cl}} / K_{\max }$. At $K_{\max }=17.7 \mathrm{MPa} V \mathrm{~m}, K_{\mathrm{cl}} / K_{\max }$ was approximately $42 \%$ and this ratio rose linearly with decreasing $K_{\max }$ and reached approximately $72 \%$ at the threshold. However, Fig. 7 shows that under the same conditions, $R=$ 0.3 and room temperature, the magnitude of $K_{\mathrm{cl}}$ is constant at $8.7 \mathrm{MPa} V \mathrm{~m}$ as $K_{\max }$ is decreased. This indicates that the closure level at room temperature and at a stress ratio of 0.3 is essentially independent of $K_{\max }$.

For closure at $500^{\circ} \mathrm{C}$ a different phenomenon seems to be involved. At all the $R$-ratios studied, normalized closure at $500{ }^{\circ} \mathrm{C}, K_{\mathrm{cl}} / K_{\max }$, was constant indicating that $K_{\mathrm{cl}}$ is a linearly increasing function of $K_{\max }$. For the same value of $K_{\max }$ increasing the $R$-ratio from 0.1 to 0.5 resulted in an increase in the magnitude of $K_{\mathrm{cl}}$. At $500{ }^{\circ} \mathrm{C}$ and an $R$-ratio of $0.3, K_{\mathrm{cl}}$ was only $50 \%$ of $K_{\max }$ indicating that at $500^{\circ} \mathrm{C}$, $\Delta K_{\text {eff }}$ was about $50 \%$ of $K_{\max }$ over the entire range of $K_{\max }$ for which $K_{\mathrm{cl}}$ was measured. Moreover, the highest ratio of $K_{\mathrm{cl}} / K_{\max }$ at threshold was found to be at an $R$-ratio of 0.5 and was only $62 \%$. All these values of $K_{\mathrm{cl}} / K_{\max }$ at threshold were lower than the ratio of $K_{\mathrm{cl}} / K_{\max }$ measured at room temperature and an $R$-ratio of 0.3 . This type of behaviour is expected for plasticity-induced closure where the degree of closure is dependent on the size of the plastic wake zone left behind the crack tip.

\section{Discussion}

In agreement with previous studies on other materials it has been shown that for the ferritic stainless steel used in this investigation, the influence of raising temperature on the FCG rates at $R=0.1$ is, in general, marked by an increase of growth rates in the mid-range regime and a decrease of $\Delta K_{\mathrm{th}}$. At $500{ }^{\circ} \mathrm{C}$, on the other hand, $\Delta K_{\text {th }}$ increased by $44 \%$ over the room temperature value, resulting in the crossover phenomenon. Others have attributed a crossover behaviour similar to that seen here to oxide-induced crack closure, which is increasingly significant at elevated temperatures, especially at low $R$-ratios. Liaw et al ${ }^{17}$ reported values of $\Delta K_{\text {th }}$ of 7.6 and $8.9 \mathrm{MPa} V \mathrm{~m}$ at room temperature and $427^{\circ} \mathrm{C}$, respectively, at $R=0.1$. However, at $R=0.8, \Delta K_{\text {th }}$ changed only from approximately 3.6 to $3.2 \mathrm{MPa} V \mathrm{~m}$ at the same temperatures, consistent with the type of behaviour expected from oxide-induced crack closure. Support for oxide-induced crack closure is also available from the work of McEvily $e t$ $a l^{18}$ who show that even at a constant elevated temperature, environmental effects can be responsible for a similar crossover behaviour between tests in air and in vacuum. Van Stone and Krueger, ${ }^{19}$ in a study of elevated-temperature fatigue crack growth in the nickel-based superalloy DA 718 , show that a 

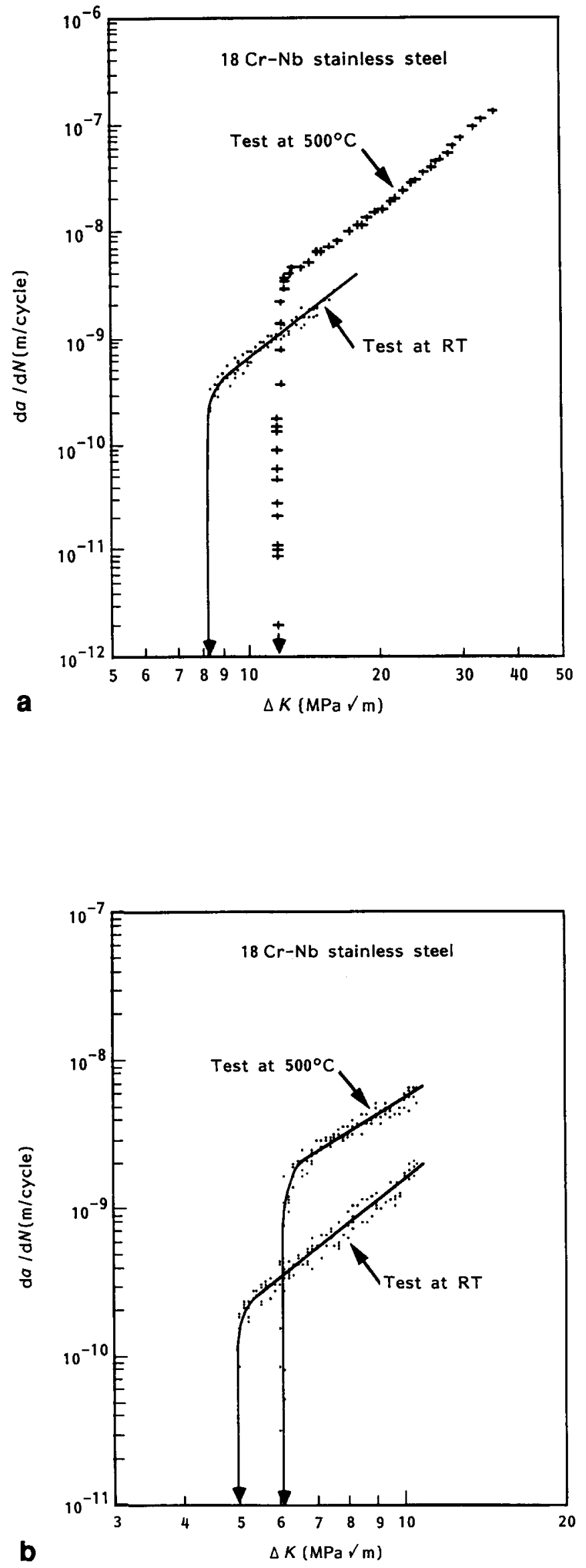

Fig. 4 The room temperature and $500^{\circ} \mathrm{C}, 15 \mathrm{~Hz}$ fatigue crack growth results at: (a), $R=0.1 ;$ (b), $R=0.5$; (c) for the CKIR test where the final stress ratios are 0.61 at $500^{\circ} \mathrm{C}$ and 0.74 at room temperature

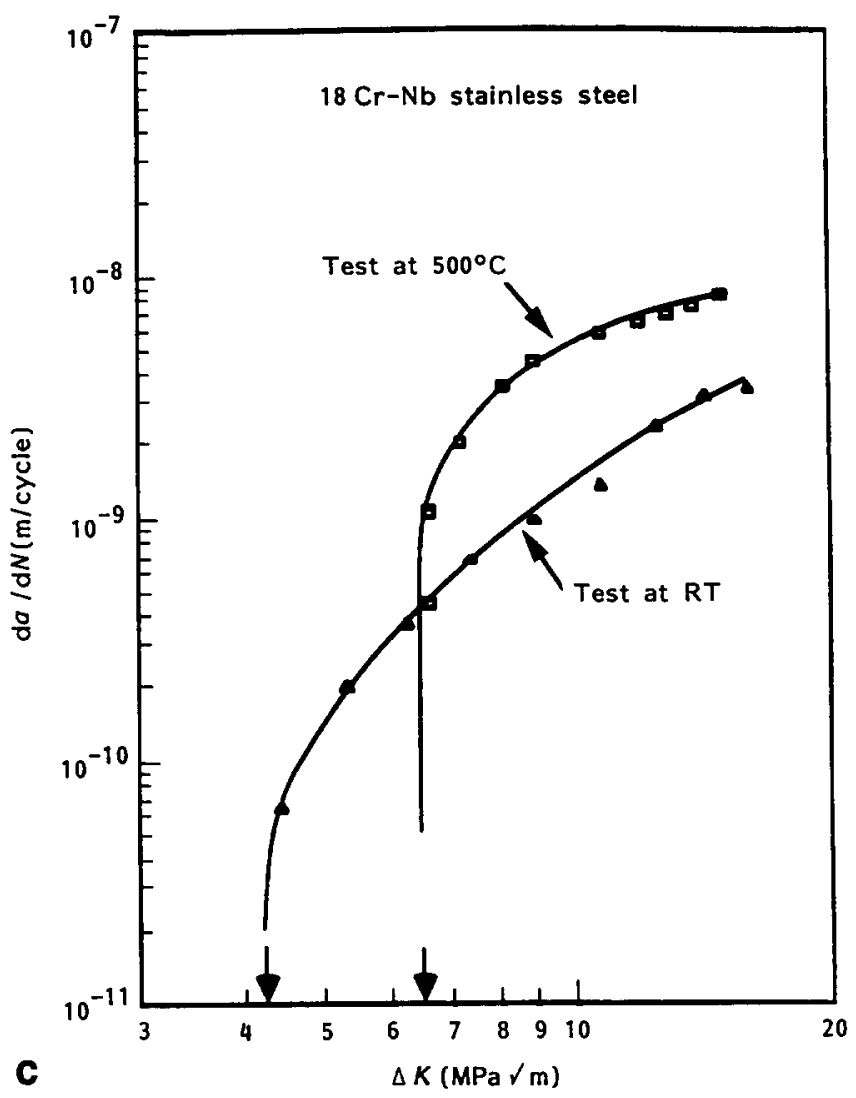

crossover type of behaviour persists to relatively high values of $R$, where oxide-induced crack closure should be insignificant. They attribute these results to local crack tip blunting resulting from a combination of creep and cyclic plasticity. However, they show no closure data to strengthen this hypothesis. In the present study the crossover type of behaviour observed at $500^{\circ} \mathrm{C}$ persists at high $R$-ratios for both constant- $R$ and CKIR tests as observed in Fig. 4 in a manner similar to that seen by Van Stone and Krueger. ${ }^{19}$ An explanation of this type of behaviour can best be gained through analysis of crack closure data at room temperature and $500{ }^{\circ} \mathrm{C}$.

First at room temperature and at $R=0.3$ the magnitude of $K_{\mathrm{cl}}$ was observed to be independent of crack length, $\Delta K$ and $K_{\max }$, and was constant at $8.7 \mathrm{MPa} V_{\mathrm{m}}$ as illustrated in Fig. 7. If plasticity-induced closure were dominant under these conditions, $K_{\mathrm{cl}}$ would be expected to increase with plastic zone size and, therefore, with $K_{\max }$, a condition not observed here. Similarly, it is doubtful that oxide-induced closure is significant because of the low test temperature and the fact that for this type of closure $K_{\mathrm{cl}}$ should increase rapidly as the threshold is approached. ${ }^{20,21}$ It has been shown ${ }^{6,22}$ that $K_{\mathrm{cl}}$ for asperity-induced closure can be correlated with the fracture surface roughness, which remains relatively constant as $\Delta K$ or $K_{\max }$ changes. It is well documented that near threshold the maximum plastic zone sizes are typically less than the grain size dimension, ${ }^{23,24}$ causing the crack to propagate by a single shear mechanism promoted by the mode-II displacement component. ${ }^{25,26}$ This produces a tortuous fracture path and results in faceted fracture surfaces that promote roughness-induced crack closure. Figure 8 , which shows the fracture path and the crystallographic nature of the fracture surface near threshold and at room temperature, indicates that roughness-induced crack closure is a possible closure mechanism in this material. Thus, the present exper- 


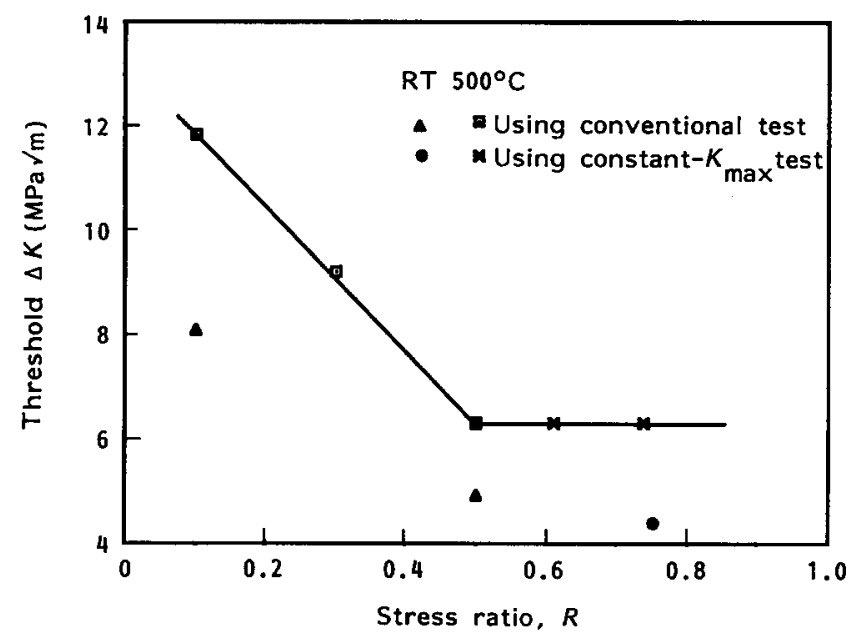

Fig. 5 Variation of $\Delta K$ threshold with respect to $R$-ratio for tests conducted at room temperature and $500^{\circ} \mathrm{C}$ at $15 \mathrm{~Hz}$

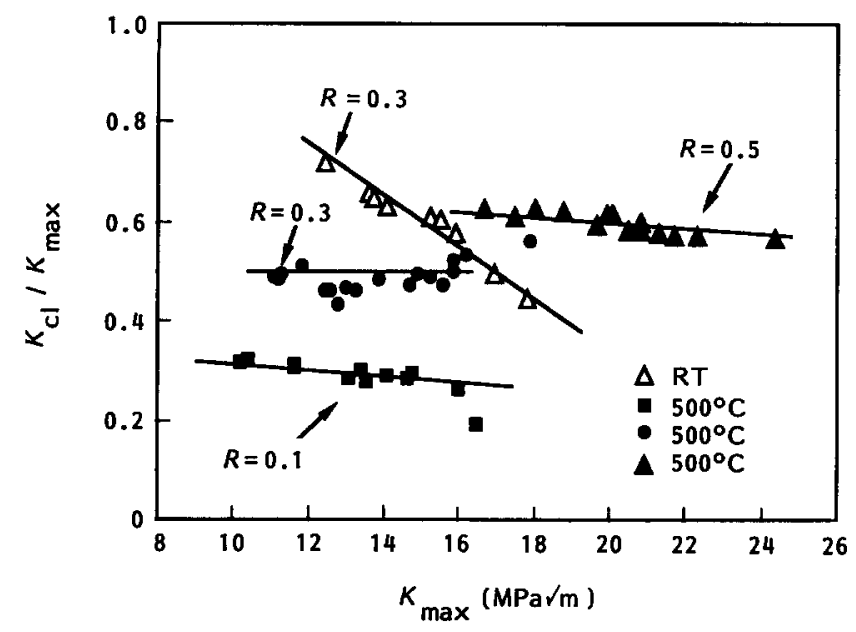

Fig. 6 Relationships between $K_{\mathrm{cl}} / K_{\max }$ and $K_{\max }$ for $R=0.1$, 0.3 and 0.5 . Tests were at room temperature and at $500^{\circ} \mathrm{C}$

imental evidence suggests that roughness-induced closure is the predominant closure mechanism at room temperature and $R=0.3$.

However, at $500^{\circ} \mathrm{C}$ and at $R$-ratios of $0.1,0.3$ and 0.5 , $K_{\mathrm{cl}}$ levels increased with increasing $K_{\max }$ and with increasing $R$-ratio. This type of behaviour would be expected only for plasticity-induced closure where the degree of closure is dependent on the size of the plastic wake left behind the crack tip. It is well established that the plastic zone size at the crack tip is proportional to $\left(K / \sigma_{y}\right)^{2}$ and, as a result, a larger amount of closure would occur at a higher value of the stress intensity factor. Furthermore, increasing the test temperature would result in a decrease in the yield strength as illustrated in Table 2, a phenomenon that would increase the plasticity at the crack tip. Thus, the effect of combining a higher $R$-ratio and a higher temperature would result in an increase of plasticity at the crack tip, and therefore, significant plasticity-induced crack closure at $500^{\circ} \mathrm{C}$.

The crack closure measurements at room temperature and $500^{\circ} \mathrm{C}$ indicate that at a stress ratio of 0.3 the dominant closure mechanism is roughness-induced closure at room temperature and plasticity-induced closure at $500^{\circ} \mathrm{C}$. At $R$ ratios of 0.1 and 0.5 , and at $500^{\circ} \mathrm{C}$, the closure mechanism remains a plasticity-induced one as indicated by the data

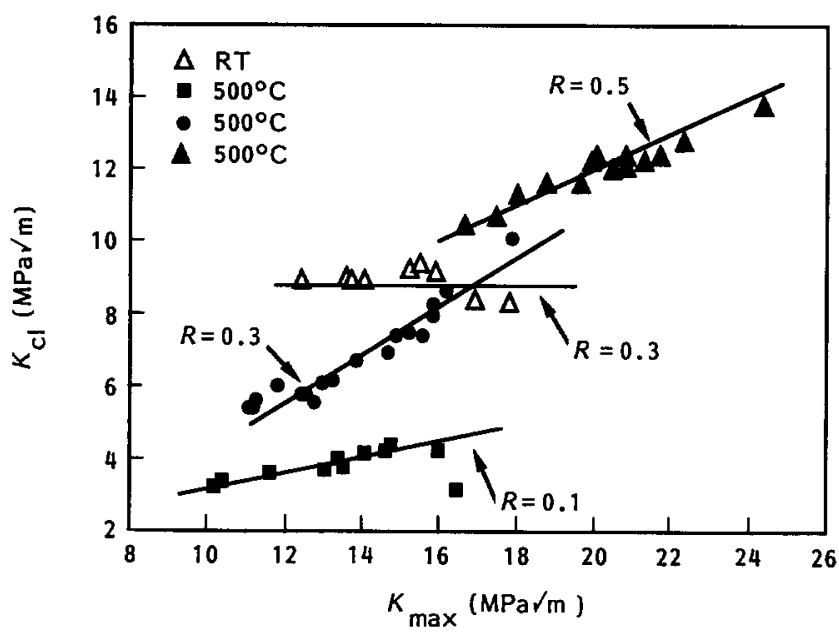

Fig. 7 Relationships between $K_{\mathrm{cl}}$ and $K_{\max }$ for $R=0.1,0.3$ and 0.5 . Tests were at room temperature and at $500^{\circ} \mathrm{C}$

shown in Fig. 7. Therefore, in the ferritic stainless steel studied here, the crossover type of behaviour observed between room temperature and $500^{\circ} \mathrm{C}$ is caused by plasticityinduced closure, which is dependent on $K_{\mathrm{max}}$, as indicated by Fig. 7, rather than by another mechanism.

At 600 and $700{ }^{\circ} \mathrm{C}$, no crossover occurred and $\Delta K_{\text {th }}$ decreased with increasing temperature. The closure mechanism that is thought to be operating at $500{ }^{\circ} \mathrm{C}$ did not influence the growth rates which decreased smoothly to the threshold levels. The occurrence of non-closure, or at least reduced closure, at 600 and $700{ }^{\circ} \mathrm{C}$, is probably the result of crack tip blunting caused by an extensive amount of plasticity at the crack tip. The increase of plasticity at the crack tip is expected as a result of the continued fall in the yield strength with increasing test temperature as shown in Table 2. It is clear that the yield strength fell significantly at 600 and $700{ }^{\circ} \mathrm{C}$ to 170 and $88 \mathrm{MPa}$, respectively, from $324 \mathrm{MPa}$ at room temperature. This fall in the yield strength results in an extensive amount of plasticity at the crack tip. At a constant value of $K_{\max }$ and $R$-ratio, the theoretical plastic zone size would have increased by factors of 3.6 and 13.5 as the temperature was raised to 600 and $700{ }^{\circ} \mathrm{C}$, respectively, and the accompanying increase in crack tip displacements in all likelihood leads to a loss of the crack tip closure effects normally associated with plasticity-induced closure.

At $500^{\circ} \mathrm{C}$ and room temperature, $\Delta K_{\text {th }}$ can be correlated by the following equations: $\Delta K_{\text {th }}=13.21(1-R)^{1.055}$ for $R$ ratios lower than 0.5 and $\Delta K_{\mathrm{th}}=8.95(1-R)^{0.845}$ for $R$-ratios lower than 0.57 , respectively. Above these critical values, $\Delta K_{\mathrm{th}}$ remained constant and equal to $6.3 \mathrm{MPa} V_{\mathrm{m}}$ and 4.4 $\mathrm{MPa} V_{\mathrm{m}}$, respectively. It is noteworthy that these values were the same as $\Delta K_{\text {th }}$ generated by the CKIR test procedure and can be considered to be the intrinsic fatigue crack propagation resistance, $\Delta K_{\mathrm{th}}^{\mathrm{i}}{ }^{27}$

The CKIR test procedure is assumed to provide conservative values for the thresholds because the monotonic plasticzone dimension at the crack tip remains constant during the entire experiment and thus the delay effects resulting from a decrease in $K_{\max }$ or $P_{\max }$ would be minimized or avoided. Also, these results suggest that the CKIR test procedure is useful for elevated-temperature testing, especially in lower strength materials where the high $R$-levels and, correspondingly, high initial $K_{\max }$ levels required to produce closure-free values of $\Delta K_{\text {th }}$ using conventional test procedures would cause excessive crack tip plasticity. 

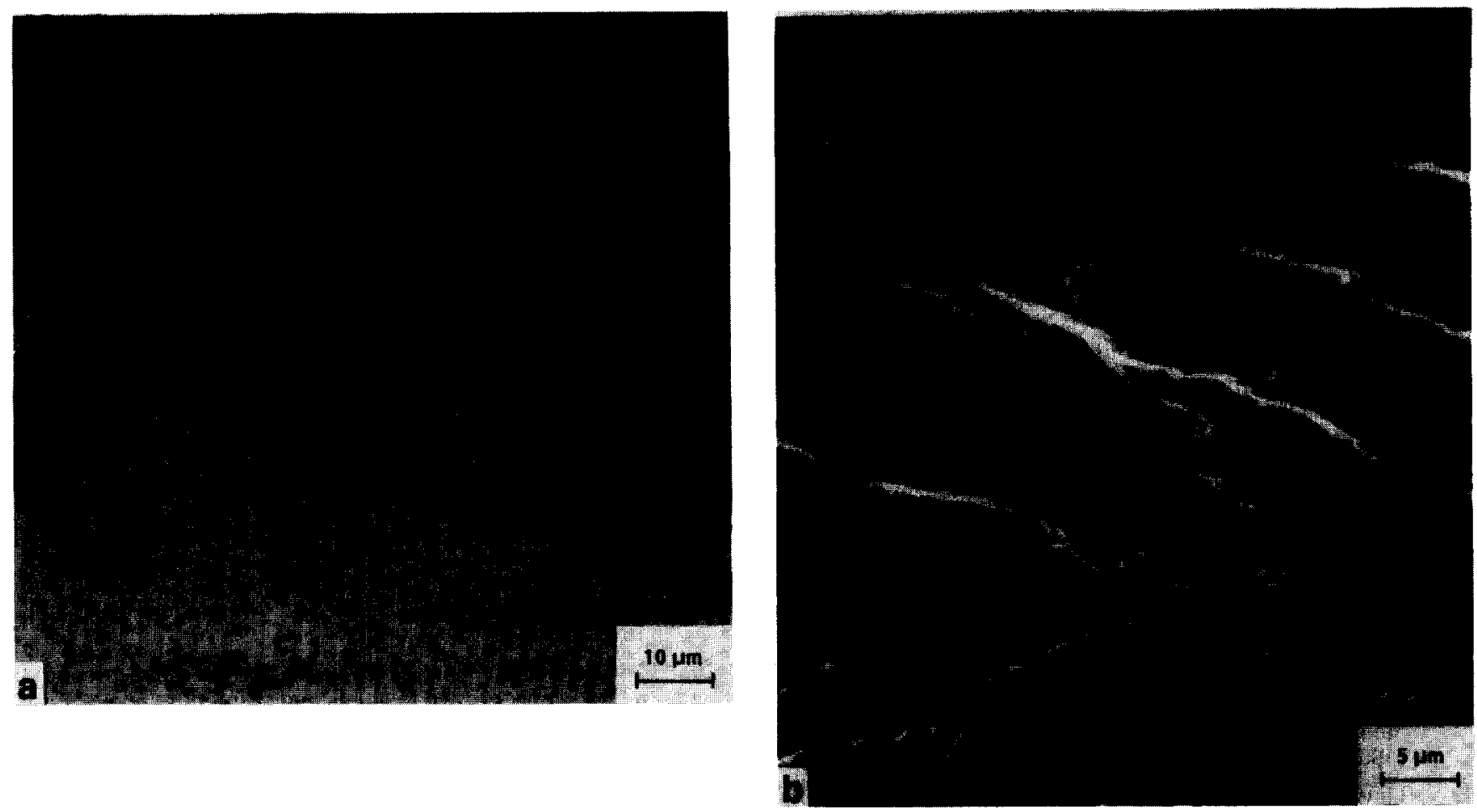

Fig. 8 (a) Optical micrograph showing the tip of a fatigue crack at room temperature and threshold. (b) SEM fractograph showing the appearance of the fracture surface at room temperature and threshold

\section{Conclusions}

Based on this study of fatigue crack growth in $18 \% \mathrm{Cr}-\mathrm{Nb}$ stabilized ferritic stainless steel at different temperatures and $R$-ratios, the following conclusions can be made.

1) At a load ratio of 0.1 increasing the test temperature from 25 to $500^{\circ} \mathrm{C}$ resulted in significant increases in mid-range growth rates and in the threshold stress intensity range, $\Delta K_{\mathrm{th}}$, resulting in a crossover type of behaviour. This crossover behaviour was presumed to be caused by crack closure. At 600 and $700{ }^{\circ} \mathrm{C} \Delta K_{\text {th }}$ decreased as a result of the loss of crack closure.

2) At near-threshold levels (below $10^{-9} \mathrm{~m} / \mathrm{cycle}$ ) and at $500^{\circ} \mathrm{C}$, near-threshold fatigue crack growth rates increased markedly and $\Delta K_{\text {th }}$ decreased with increasing $R$-ratio from 0.1 to 0.5 . Above $0.5 \Delta K_{\text {th }}$ remained constant at $6.3 \mathrm{MPa} V \mathrm{~m}$. At room temperature a similar type of behaviour was observed, except that the critical $R$-ratio below which growth rates and $\Delta K_{\text {th }}$ were sensitive to variations in $R$ was 0.57 .

3) The CKIR test procedure at $500^{\circ} \mathrm{C}$ and at two levels of $K_{\max }$ exhibited thresholds very close to the high $R$ independent values obtained by conventional testing. Moreover, the CKIR test procedure was found to be very useful at elevated temperature where excessive crack tip plasticity would have complicated the measurements if the conventional procedure was utilized at high $R$-ratios.

4) At room temperature $K_{\mathrm{cl}}$ was found to be independent of $K_{\max }$, indicating that asperity-induced closure dominates; whereas, at $500^{\circ} \mathrm{C}$, at all the $R$-values studied, $K_{\mathrm{cl}}$ increased with increasing $K_{\max }$, indicating that a transition to plasticity-induced closure occurred at $500^{\circ} \mathrm{C}$, and that plasticity-induced crack closure was primarily responsible for the crossover phenomenon observed in this study.

\section{Acknowledgements}

We gratefully acknowledge the financial support of the AC Rochester Division of General Motors Corporation and the advice of Dr Gamdur Mann. We are also grateful to Mr L. Carol for providing the test materials and the elevatedtemperature mechanical property data.

\section{References}

1. Ritchie, R.O. 'Near-threshold fatigue crack propagation in steels' Int Met Rev 24 5/6 (1979) pp 206-230

2. 'Standard test method for measurement of fatigue crack growth rates' ASTM E647-88A (American Society for Testing and Materials, 1988)

3. Herman, W.A., Hertzberg, W.R. and Jaccard, R. 'A simplified laboratory approach for the prediction of short crack behavior in engineering structures' Fatigue Fract Eng Mater Struct 114 (1988) pp 303-320

4. Yuen, J.L. and Roy, P. 'Influence of temperature on the near threshold FCG behavior of a nickel base supperalloy' Fatigue Crack Growth Threshold Concepts (The Metallurgical Society of AIME, Warrendale, PA, 1984) pp 185-203

5. Allison, J.E. and Williams, J.C. 'Near-threshold fatigue crack growth phenomena at elevated temperature in titanium alloys' Scr Metall 19 (1985) pp 773-778

6. Gray, G.T., III, Williams, J.C. and Thompson, A.W. 'Roughness-induced crack closure: an explanation for microstructurally sensitive fatigue crack growth' Metall Trans A 14A 3 (1983) pp 421-433

7. Pendse, R.D. and Ritchie, R.O. 'A study of fatigue crack propagation in prior hydrogen attacked pressure vessel steels' Metall Trans A 16A 8 (1985) pp 1497-1501

8. Elber, $W$. 'The significance of fatigue crack closure' Damage Tolerance in Aircraft Structures, ASTM STP 486 (American Society for Testing and Materials, 1971) pp 230-242

9. Docker, H., Bachmann, V. and Marci, G. 'A comparison of different methods of determination of the threshold 
for fatigue crack propagation' Proc Int Conf on Fatigue Thresholds, Stockholm, Sweden, 1981 (EMAS, Warley, UK, 1982) Vol I pp 45-57

10. Hertzberg, R.W., Herman, W.A. and Ritchie, R.O. 'Use of constant $K_{\text {max }}$ test procedure to predict small crack growth behavior in 2090-T8E41 aluminum-lithium alloy' Sor Metall 21 (1987) pp 1541-1546

11. Herman, W.A. 'A re-evaluation of fatigue threshold test procedures and the simulation and prediction of fatigue crack growth under conditions of low crack closure' PhD Thesis (Lehigh University, USA, 1988)

12. Carol, L.A. private communication, 1989

13. Brook, D. Elementary Engineering Fracture Mechanics 3rd edn (Martinus Nijhiff, The Hague, 1982) p 76

14. Allison, J.E. 'The measurement of crack closure during fatigue crack growth' Frocture Mechanics: Eighteenth Symp, ASTM STP 945 (American Society for Testing and Materials, 1988) pp 913-933

15. Donald, J.K. 'A procedure for standardizing crack closure levels' Mochanics Fatigue Crack Closure, ASTM STP 982 (American Society for Testing and Materials, 1988) pp 222-229

16. Ritchie, R.O., Suresh, S. and Moss, C.M. 'Near-threshold fatigue crack growth in $2.25 \mathrm{Cr}-1 \mathrm{Mo}$ pressure vessel steel in air and hydrogen' J Eng Mater Technol 102 (1980) pp 293-299

17. Liaw, P.K., Saxena, A., Swaminathan, V.P. and Shih, T.T. 'Influence of temperature and load ratio on near-threshold fatigue crack growth behavior of CrMoV steel' Fatigue Crack Growth Threshold Concepts (The Metallurgical Society of AIME, Warrendale, PA, 1984) pp 205-223

18. McEvily, A.J., Minakawa, K. and Nakamura, H. 'Fatigue crack growth at elevated temperature in ferritic steels' Advanced Materials for Severe Service Applications (Elsevier Applied Science, Amsterdam, 1987) pp 291-301

19. Van Stone, R.H. and Krueger, D.D. 'Near-threshold crack growth in nickel base superalloys' Fracture Mechanics: Nineteenth Symp, ASTM STP 969 (American Society for Testing and Materials, 1988) pp 883-906
20. Allicon, J.E. 'The measurement of crack closure during fatigue crack growth' Fracture Mechanics: Eighteenth Symp. ASTM STP 945 (American Society for Testing and Materiais, 1988) pp 913-933

21. Liaw, K.P. 'Overview of crack closure at near-threshold fatigue crack growth levels' Mechanics of Fatigue Crack Closure, ASTM STP 982 (American Society for Testing and Materials, 1988) pp 62-92

22. Altison, J.E. 'The influence of slip character and microstructure on FCG in $\alpha$ and $\alpha+\beta$ titanium alloys' PhD Thesis (Carnegie-Mellon University, USA, 1982)

23. Suresh, S. and Ritchie, R.O. 'A geometric model for fatigue crack closure induced by fracture surface roughness' Metall Trans A 13A 9 (1982) pp 1627-1631

24. McCarver, J.F. and Ritchie, R.O. 'Fatigue crack propagation thresholds for long and short cracks in René 95 nickel-base superalloy' Mater Sci Eng 55 (1982) pp 63-67

25. Lindley, T.C. 'Near-threshold fatigue crack growth: experimental methods, mechanisms and applications' Subcritical Crack Growth Due to Fatigue, Stress Corrosion and Creep (Elsevier Applied Science, Amsterdam, 1981) pp 167-213

26. Minakawa, K. and McEvily, A.J. 'On near-threshold fatigue crack growth in steels and aluminium alloys' Proc Int Conf on Fatigue Thresholds, Stockholm, Sweden, 1981 (EMAS, Warley, UK, 1982) Vol I pp 373-390

27. Suresh, S. and Ritchie, R.O. 'On the influence of environment on the load ratio dependence of fatigue thresholds in pressure vessel steel' Eng Fract Mech 184 (1983) pp 785-800

\section{Authors}

Kamel Makhlouf, graduate research assistant, and J.W. Jones, associate Professor, are with the Department of Materials Science and Engineering, The University of Michigan, Ann Arbor, MI 48109, USA. Received 22 September 1991; accepted 11 October 1991. 